\title{
INTERACTIONS OF PHEROMONE COMPONENT ODOR PLUMES OF WESTERN PINE BEETLE ${ }^{1,2}$
}

\author{
JOHN A. BYERS \\ Department of Animal Ecology, University of Lund \\ $S$-223 62 Lund, Sweden \\ Department of Entomological Sciences \\ University of California \\ Berkeley, California 94720
}

(Received August 4, 1986; accepted December 18, 1986)

\begin{abstract}
The relationships between catch of $D$. brevicomis LeC. at sources of the synergistic pheromone components, exo-brevicomin (E) and frontalin $(F)$, and increasing distance of separation of sources were investigated in the forest. The two components were each released with the host monoterpene, myrcene (M), in trap pairs. The traps of each pair were spaced apart at various distances $(0-16 \mathrm{~m})$ in either horizontal or vertical lines that were perpendicular to the mean wind direction. Both sexes were most strongly attracted when the two components were released from the same source, and increasing distance of separation between components caused exponential decreases in trap catch for all trap configurations. Males were significantly more attracted to traps with $\mathrm{E}, \mathrm{M}$ alone than to corresponding traps with $\mathrm{F}, \mathrm{M}$ alone, while females exhibited a preference for $F, M$. The theoretical relationships and properties of two coalescing plumes of individual components and their intersecting "active space" are presented and discussed. It is proposed that "confusion" or "communication disruption" techniques for insect control may be more successful if components are released individually from many points rather than released similarly in blends.
\end{abstract}

Key Words-Dendroctonus brevicomis, Coleoptera, Scolytidae, pheromone, synergism, plumes, exo-brevicomin, frontalin, myrcene.

'Dendroctonus brevicomis LeC. (Coleoptera: Scolytidae).

${ }^{2}$ Supported in part by grants from U.S.A. and Sweden, NSF (INT-8503520), STU (84-3937), NFR, FRN, and SJFR. 


\section{INTRODUCTION}

To date there has been very little research on the theoretical and biological consequences of physically separating the release points of individual pheromone components that normally would be released together. There are several reasons why research on the interactions of pheromone component odor plumes is of interest to chemical ecologists. From a practical standpoint, it may be that "confusion methods," which disrupt pheromone communication, are more effective if synergistic components are released separately in disjointed blends than if full blends are released. From a field test design standpoint, it is of importance to understand how far apart traps of different component blends must be placed in order to minimize interactions and yet take advantage of "homogeneous" populations levels found in a particular area. Finally, it is of basic interest to determine the physical dimensions of synergistic component interaction for various species and their sexes.

There are two major ways that a semiochemical treatment in a trap can interfere with the catches of insects in nearby traps containing different treatments. In the first way, semiochemicals can affect the responses of insects at distances from the source that include the adjacent traps. For instance, traps releasing high concentrations of attractants may cause high numbers of insects to enter the vicinity and some could be caught incidentally on nearby traps and thus artificially increase their catches. Schlyter et al. (1987a) found that highreleasing pheromone traps did increase the catch of the bark beetle Ips typographus on nearby blank traps as well as lower-releasing traps, presumably by attracting large numbers of beetles into the area. They also found that the catch on the adjacent traps became increasingly greater as the distances between traps were decreased. The second way that semiochemical treatments can affect the catches on adjacent traps is by synergistic component odor plume interactions. This has not been studied with insects in the field and is the focus of this paper.

The Western pine beetle Dendroctonus brevicomis LeConte (Coleoptera: Scolytidae), provides an appropriate system for investigations into the interactions of pheromone component odor plumes because of its sex-specifically-produced synergistic components. The female begins the colonization of ponderosa pine (Pinus ponderosa Doug. ex. Laws.) when she bores through the outer bark and excavates a gallery in the phloem layer. She produces a pheromone synergist, exo-brevicomin (E), which accumulates in her hindgut upon feeding (Pitman et al., 1969; Hughes and Renwick, 1977; Byers et al., 1984) and is released with the fecal pellets in the frass (Silverstein et al., 1968). Although Libbey et al. (1974) found that females in glass tubes could release small amounts of $E$ without feeding, it appears most $E$ is released during feeding. A male attracted to the entrance tunnel soon releases frontalin (F) (Kinzer et al., 1969; Libbey et al., 1974; Browne et al., 1979), and it appears he is capable 
of doing so immediately upon defecation (Byers et al., 1984). F, together with $E$, synergistically enhances the attraction of both sexes, with a small further increase due to the host resin monoterpene, myrcene (M) (Wood et al., 1976; Bedard et al., 1980). This synergism results in a dramatic increase in beetle visitation and cooperative "mass attack" which functions to overcome the resinous defense mechanisms of the host tree (Wood, 1982).

In several earlier reports, the female-produced $\mathrm{E}$ was found to attract primarily males, while the male-produced $F$ attracted mostly females (Bedard et al., 1969; Vité and Pitman, 1969a,b; Pitman and Vité, 1971; Hughes and Pitman, 1970). However, it must be understood that release of $F$ alone probably does not occur in nature because males always join females in their galleries. On the other hand, it is possible for males to release $F$ upon landing on the tree as large quantities are present in their hindguts (Byers et al., 1984). Vité et al. (1972) proposed that $D$. brevicomis could release pheromone upon landing with a "contact pheromone" as opposed to the feeding-dependent pheromone components of many Ips species ("frass pheromone"). Wood et al. (1976) determined that only the $(+)-E$ and the $(-)-F$ enantiomers were bioactive. Furthermore, the presence of inactive enantiomers in the racemic mixtures did not cause inhibition or inactivation.

The objectives investigated here are: (1) What are the relationships between the distance of separation, either horizontal or vertical, of release points of the synergists, E and F, and the attraction of each sex to these sources? (2) What are the theoretical mathematical relationships among the ratios of the pheromone component concentrations at various places in the intersecting odor plumes for varying degrees of intersection?

\section{METHODS AND MATERIALS}

Interacting Exo-brevicomin $(E)$ and Frontalin $(F)$ Odor Plumes. All experiments were conducted at two sites (A and B) in the Sierra National Forest near Bass Lake, Madera County, California, at about $1000 \mathrm{~m}$ elevation. In September 1978, a test was conducted at site A with pairs of tubular sticky traps (19 cm diam. $\times 30.5 \mathrm{~cm}$ high, 6.3-mm wire mesh coated with Stickem Special), each supported on a pipe standard $1.2 \mathrm{~m}$ above the ground. One trap of a pair contained a release device (Byers and Wood, 1980) that had a glass tube $(52 \mathrm{~mm} \times 3.5 \mathrm{~mm}$ ID) with $\mathrm{E}(>95 \%$ and no $\mathrm{F}$ by GLC) and another with myrcene $(M)(>97 \%)$, while the other trap contained $M$ and a glass tube $(62$ $\mathrm{mm} \times 2.2 \mathrm{~mm}$ ID) with $\mathrm{F}$ (>95\% with no $\mathrm{E}$ by GLC). The chemicals from Chem. Samples Co., Cleveland, Ohio, were each released at about $2 \mathrm{mg} /$ day under field conditions (Browne, 1978) or somewhat less at about $1.5 \mathrm{mg} / \mathrm{day}$ according to Tilden and Bedard (1985). Eleven 1-day-long, replicates were ob- 
tained on each of five trap pairs horizontally spaced apart at distances of 0,2 , 4,8 , and $16 \mathrm{~m}$. The trap pairs were oriented perpendicular to the mean wind direction and were randomized in different areas, which were at least $25 \mathrm{~m}$ apart, each day. Beetles were collected each day, cleaned in solvent, and sex was determined.

In August 1985, a similar test at site B was conducted for six, 1-day-long, replicates but at distances of $0,0.5,1.5$, and $3 \mathrm{~m}$ between traps in a pair. At the same time, at site B, a test of trap pairs (baited the same way) vertically spaced apart at distances of $0,0.5,1.5$, and $3 \mathrm{~m}$ was conducted. The "bottom" traps were placed at $1.2 \mathrm{~m}$ height with the "top" trap at the respective distances above the bottom trap. Trap pairs were switched each day (1-day-long replicates) so that top and bottom placements occurred equally among the treatments, while randomization of trap pairs between areas occurred every second day, three times.

Treatment effects within pairs were analyzed by Wilcoxon matched-pair tests both for total catch and male-female numbers. The sex ratios of catch on treatments within and between trap pairs were determined as were $95 \%$ binomial confidence limits (Byers and Wood, 1980), and chi-square tests were performed to test for differences. A nonlinear relationship between trap catch and distance of component separation may be expected based on the nature of the wind-plume interactions over time. Therefore, several linear and nonlinear regressions were performed to determine which curve best fits the data (linear, logarithmic, exponential, power, $Y=a+b X^{2}$, and $\left.Y=a+b / X\right)$. This was done to be able to predict catches at various distances not tested here. Exponential regression was found to fit the data best (highest $r^{2}$ values) and was used to draw the lines in Figures 1-3.

Theoretical Model of Interactions of Odor Plumes. Elkinton and Cardé (1984) show the Gaussian distribution of the "active space" of pheromone concentration for a 3-min time-averaged plume as modified from Slade (1968). In Figure 4, two such plumes have been intersected. Based on the understanding of this figure, one can theorize about the concentrations of each component when the component odor plumes have specified standard deviations and distances of separation. It can be assumed that both $\mathrm{E}$ and $\mathrm{F}$, which have similar molecular weights and volatilities, will have similar Gaussian plumes. Thus, the shape of the intersection area of the plumes where both compounds are present (Figure 5) and the intersection midline where the ratio is $1: 1(H)$ can be calculated iteratively by computer from the normal probability density function:

$$
\int \mathrm{rel}=1 /(\sigma \sqrt{2 \pi}) e^{-(x-\mu)^{2} /\left(2 \sigma^{2}\right)}
$$

where $\sigma$ is the standard deviation (1), $\mu$ is the mean (4.5 or 7.5), and $x$ is any point on the $x$ axis. The above equation can be used to solve for $H=\left(\int \mathrm{rel}\right)$ at 


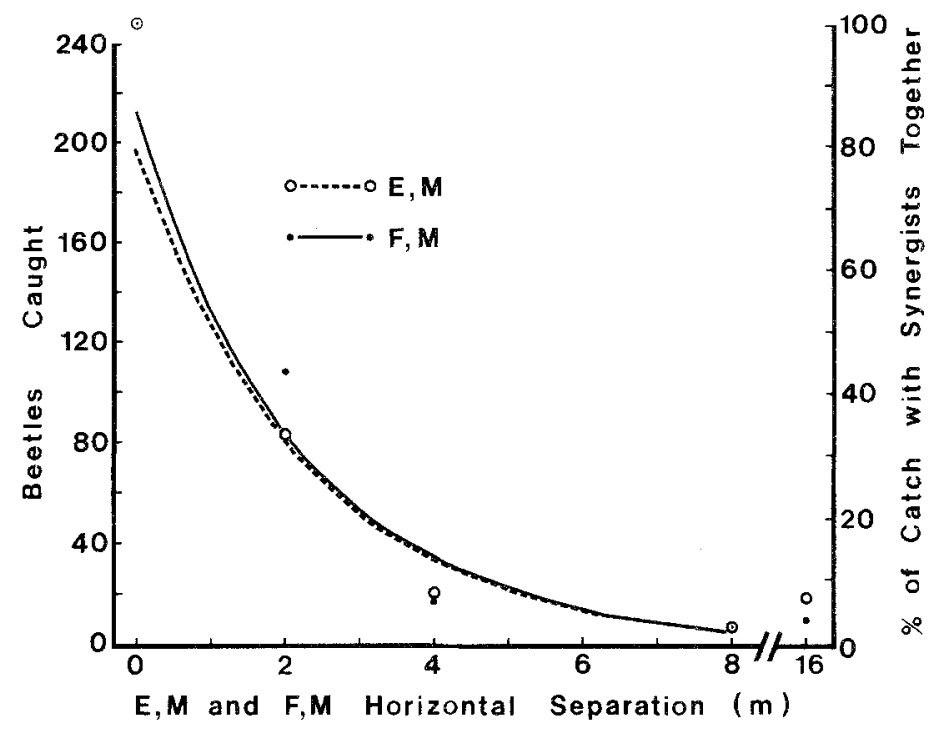

FIG. 1. Reduction in catch of $D$. brevicomis at sources of the pheromone synergists exobrevicomin $(E)$ and frontalin $(F)$ with increasing horizontal distance of separation between sources. Each point represents a total of 11 one-day replicates. The pheromone components, each with myrcene $(\mathrm{M})$, were each released at about $1.5 \mathrm{mg} /$ day from sticky traps at $1.5 \mathrm{~m}$ height in the Sierra National Forest, California (September 17-28, 1978).

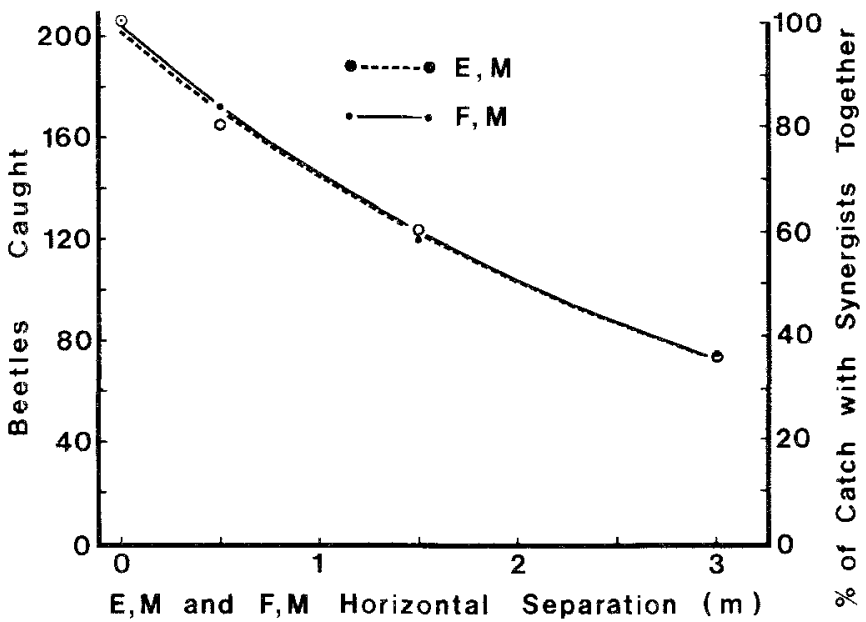

FIG. 2. Reduction in catch of $D$. brevicomis at sources of the pheromone synergists exobrevicomin (E) and frontalin (F) with increasing horizontal distance of separation between sources. Each point represents a total of six one-day replicates. The pheromone components, each with myrcene $(\mathrm{M})$, were each released at about $1.5 \mathrm{mg} / \mathrm{day}$ from sticky traps at $1.5 \mathrm{~m}$ height in the Sierra National Forest, California (August 20-26, 1985). 


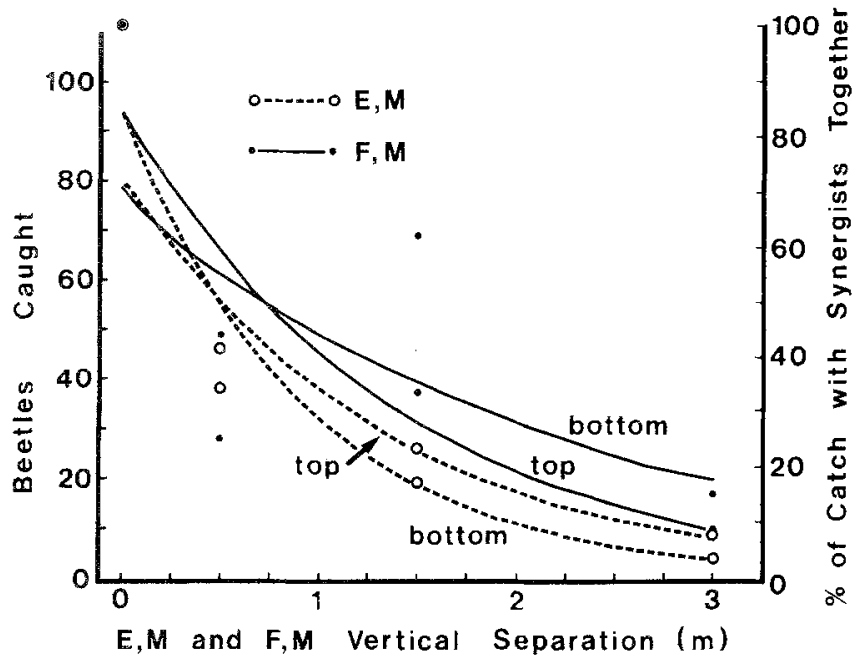

FIG. 3. Reduction in catch of $D$. brevicomis at sources of the pheromone synergists exobrevicomin $(\mathrm{E})$ and frontalin $(\mathrm{F})$ with increasing vertical distance of separation between sources. Each point represents a total of three 1-day replicates. The pheromone components, each with myrcene $(M)$, were each released at about $1.5 \mathrm{mg} /$ day from sticky traps at $1.5 \mathrm{~m}$ (bottom trap) or more height (top trap) in the Sierra National Forest, Califomia (August 20-26, 1985).

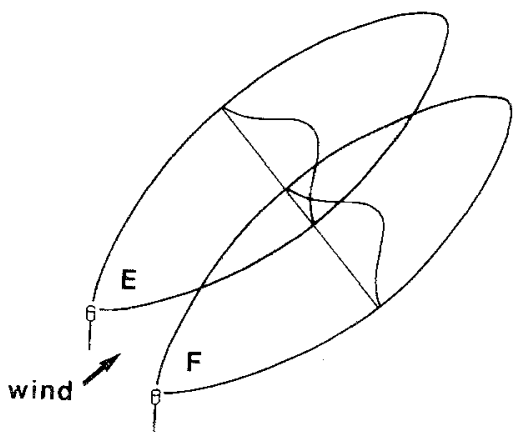

FIG. 4. Diagrammatic representation of the "active space" intersection area (shaded area) of two synergistic Gaussian plumes with 3-min averaging times (modified from Elkinton and Cardé after Slade, 1968). 


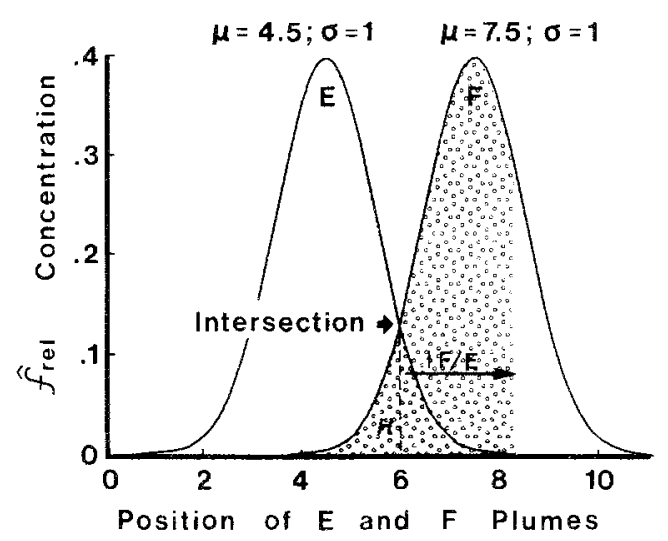

FrG. 5. Graphic representation of the cross-section of the concentration distributions of two Gaussian plumes of the pheromone synergists ( $E$ and F). The "active space" is related to the height of the dashed line $(H)$ and the width of the shaded area, and it does not have a Gaussian distribution as do $\mathrm{E}$ or $\mathrm{F}$ with means of 4.5 or 7.5 and standard deviations of 1. Flight-path deviations along the $x$ axis, for example to the right, would increase the ratio of $\mathrm{F} / \mathrm{E}$ dramatically and unnaturally compared to natural pheromone plumes.

$x=6$. The height of the intersection or point where both components are equal $(H)$ can be iteratively calculated for varying degrees of plume intersection (Figure 6) with the following BASIC program that utilizes the above equation:

$$
\text { FOR } \begin{aligned}
\mathrm{W} & =\mathrm{I}+\mathrm{M} \text { TO I }+\mathrm{M}+\mathrm{S} \text { STEP SS: } \\
\mathrm{Y} & =1 /\left(\mathrm{SD}^{*} \mathrm{SQR}(2 * \mathrm{PI})\right)^{*} \operatorname{EXP}(1)^{\wedge}\left(-\left((\mathrm{I}-\mathrm{W})^{\wedge} 2\right) /\left(2 * \mathrm{SD}^{\wedge} 2\right)\right): \\
\mathrm{X} & =2 * \mathrm{M}+(\mathrm{W}-(\mathrm{I}+\mathrm{M})) * 2: \text { PRINT X, Y }: \text { NEXT W }
\end{aligned}
$$

where $I$ is the intersection point (e.g., 6), $M$ is the starting distance of either mean to intersection, $S$ is the maximum distance means will be separated, $S S$ is the step size on $x$ axis for each calculation, SD is the standard deviation of the plumes (equal for both plumes), $X$ is the $x$ axis value or separation of component plumes, and $Y$ is the $y$ axis value or $H$ of the intersection midline.

The ratio of $\mathrm{F}$ to $\mathrm{E}$ that an insect would encounter as it traverses laterally over the plume intersection area is depicted in Figure 5. The precise relationship beginning at a ratio of 1 at the intersection point $(H)$ and moving to the right is shown in Figure 7 . The results were calculated iteratively by computer assuming that the $E$ and $F$ plumes have equal standard deviations but the following equation will also work on unequal variances:

Ratio $\mathrm{F} / \mathrm{E}=\left[1 /\left(\sigma_{F} \sqrt{2 \pi}\right) e^{-(x-\mu F)^{2} /\left(2 \sigma_{F}^{2}\right)}\right] /\left[1 /\left(\sigma_{E} \sqrt{2 \pi}\right) e^{-(x-\mu E)^{2} /\left(2 \sigma_{k}^{2}\right)}\right]$ 


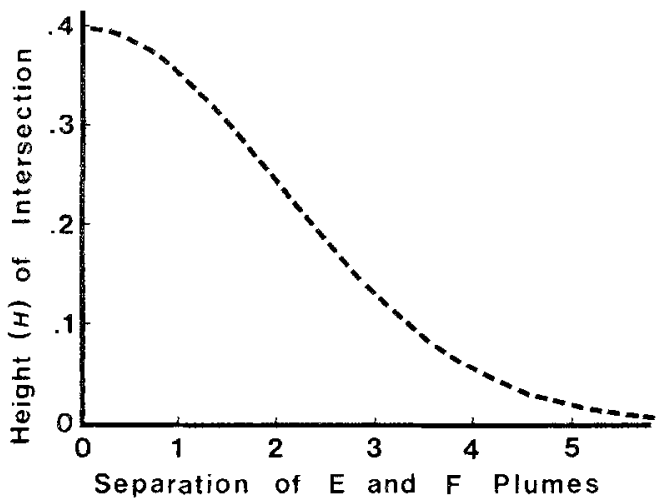

FIG. 6. Gaussian relationship between height of the intersection midline (concentration) of two separated synergist plumes (dashed line in Figure 5) and the separation distance between the longitudinal axes of the plumes.

where $\sigma_{F}$ and $\sigma_{E}$ are the standard deviations of $\mathrm{F}$ and $\mathrm{E}$, respectively, $\mu_{F}$ and $\mu_{E}$ are the means of $\mathrm{F}$ and $\mathrm{E}$, respectively, and $x$ is any point on the $x$ axis. Exponential regression was then performed on the results to obtain the equation of the curve in Figure 7.

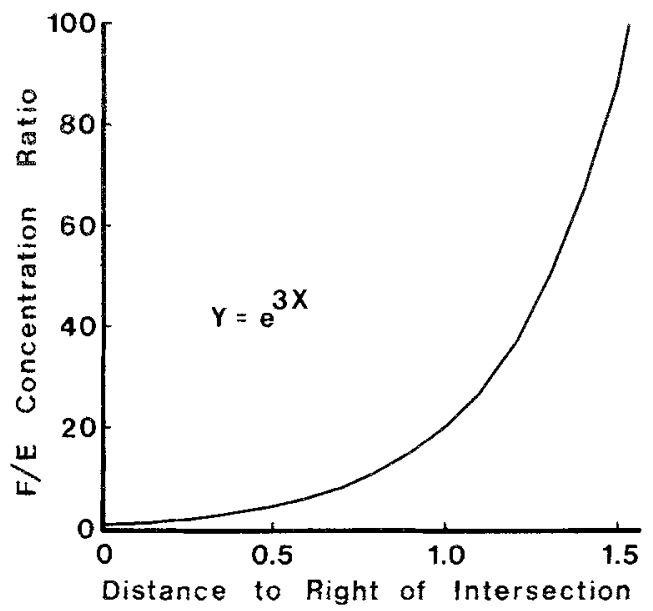

FrG. 7. Exponential relationship between the ratio of $\mathrm{F} / \mathrm{E}$ concentrations (Figure 5) within two intersecting synergist plumes and the distance to the right of the longitudinal intersection midline (dashed line in Figure 5) of the plumes. 


\section{RESULTS}

Interacting Exo-brevicomin $(E)$ and Frontalin $(F)$ Odor Plumes. The catches of $D$. brevicomis on $E, M$ and F, M trap pairs spaced apart horizontally at various distances from 0 to $16 \mathrm{~m}$ in 1978 are shown in Figure 1 . The points at $16 \mathrm{~m}$ were not used in calculating the exponential regression curves because these values were not appreciably different from those at $8 \mathrm{~m}$, indicating that interaction effects were negligible at distances $>8 \mathrm{~m}$. It can be seen that trap catches on $\mathrm{E}, \mathrm{M}\left(Y(\%)=79.62 e^{-0.448 X}, r^{2}=0.95\right)$ were similar to corresponding catches on F,M $\left(Y(\%)=85.64 e^{-0.461 X}, r^{2}=0.92\right)$ within a pair at any separation distance. The interactions between the $E$ and $F$ synergists were insignificant when the distance of their separation was increased farther than 4 $\mathrm{m}$. When the horizontal separation test was repeated in 1985 at distances from 0 to $3 \mathrm{~m}$, a similar relationship occurred (Figure 2). Again the trap catches on $\mathrm{E}, \mathrm{M}\left(Y(\%)=97.91 e^{-0.334 X}, r^{2}=1.00\right)$ were almost identical to corresponding catches on F, M $\left(Y(\%)=98.83 e^{-0.337 X}, r^{2}=1.00\right)$.

In the 1985 test of $E, M$ and F, M trap pairs spaced apart vertically at distances from 0 to $3 \mathrm{~m}$, the results have been presented with respect to the special symmetry of "top" and "bottom" (Figure 3). The catches on top and bottom traps with either E, M or F, M are similar, although F, M appears to have attracted more beetles. The relationships between percent of catch when synergists were together and the vertical separation distance for the respective traps are given by the following exponential equations: top $\mathrm{F}, \mathrm{M}(\mathrm{Y}(\%)=$ $\left.85.25 e^{-0.738 X}, r^{2}=0.95\right)$; bottom F, M $\left(Y(\%)=69.13 e^{-0.452 X}, r^{2}=0.49\right)$; top E, M $\left(Y(\%)=72.75 e^{-0.754 X}, r^{2}=0.92\right)$; bottom E, M $(Y(\%)=$ $\left.85.14 e^{-1.067 X}, r^{2}=0.99\right)$.

Although the total (male + female) catches appear similar on E, M and $F, M$ traps in the experiments (Figures 1-3), there are significant, but no dramatic, male-female differences as reflected in the Yates chi-square test and Wilcoxon matched-pair test (Table 1). In most cases, the F, M trap had a lower sex ratio (proportionately less males) than the $E, M$ trap within a pair, both for horizontally and vertically placed traps (Table 1). The Wilcoxon tests also showed, in many cases, that the distribution of male, or female, catches on the replicates within a trap pair were significantly different (Table 1). A comparison of $\mathrm{E}, \mathrm{M}$ and $\mathrm{F}, \mathrm{M}$ vertical pairs with the Wilcoxon test, without regard to position, showed that at $1.5 \mathrm{~m}$ separation the female as well as the total catches had significantly different distributions on the synergists. Also at $3 \mathrm{~m}$ separation, the male, female, and total catches had significantly different distributions $(P<0.05$, Wilcoxon). The sex ratios and $(95 \%$ binomial confidence limits) for the vertical pairs are: $E, M(\geq 0.5 \mathrm{~m})=0.84(0.64-1.10)$ and $F, M(\geq 0.5$ $\mathrm{m})=1.54(1.10-2.15)$, which were different at $P<0.05$, Yates $\chi^{2}$.

Furthermore, when the total catch on $F, M$ traps is compared to $E, M$ traps 
for all horizontally or vertically paired traps (separated by at least $0.5 \mathrm{~m}$ ), there are significant differences in the sex ratios in all cases except the "top" vertical traps (Table 1). In two of the four cases, the sex ratio on $\mathrm{F}, \mathrm{M}$ was significantly different from the control, while in the other two cases, the sex ratio on $\mathrm{E}, \mathrm{M}$ was significantly different. From the sex ratios alone it is impossible to determine if males or females or both prefer one of the synergists, but the Wilcoxon tests indicate that males prefer $E, M$ while females prefer $F, M$. The sex ratios were virtually identical on the top and bottom traps, $1.10(0.83-1.47)$ and 1.04 $(0.77-1.40)$, respectively. However, these ratios were significantly different from the control where the synergists were placed together $(P<0.05)$, although they were not different from the "horizontal control" which was placed in the same area at the same time (Table 1).

Temnochila chlorodia (Mannerheim), a predator of $D$. brevicomis and known to be attracted to E (Bedard et al., 1969), was caught in 1978 only on the traps containing $E, M$ ( 11 beetles) except for one caught on $F, M$ at the 2-m spacing. In 1985 on the horizontal traps, $T$. chlorodia were caught only on the E,M-containing traps (16 males, 6 females) except for two males and one female on the F, M traps at $1.5 \mathrm{~m}$. The vertical traps caught these predatory beetles again only on traps with E, M (18 males, 6 females) except for one male and two females on F, M at $1.5 \mathrm{~m}$ and one female on F, M at $0.5 \mathrm{~m}$.

Theoretical Model of Interactions of Odor Plumes. In Figure 4, two 3-min time-averaged plumes are shown coalescing when the mean wind direction is perpendicular to the two sources. The "active space" (cf. Elkinton and Cardé, 1984) where the two components ( $E$ and $F$ ) are both above the threshold of response (cf. Roelofs, 1978) is shown in the shaded area (Figure 4). The two bell-shaped curves represent the Gaussian distribution of concentration for each component. The "active space" as shown in Figure 4 actually is fundamentally different from the normal active space in which both components vary similarly based on a Gaussian distribution. In Figure 5 the relative concentrations of each component along the latitudinal axis are shown and demonstrate the peculiar properties of the intersection area of the two plumes. The intersection midline where the two components are of equal concentration (presumed most favorable for orientation) is represented by $H$ and the dashed line (Figure 5). If the two odor sources (shown in Figure 5) are placed together and then physically separated until the two plumes do not intersect, then the relative concentration at the intersection midline $(H)$ decreases, as shown in Figure 6 , according to a normal curve.

Referring to Figure 5, if an insect were flying upwind along the intersection midline and then veered more into the $F$ odor plume, then the ratio of $F / E$ would increase exponentially according to Figure $7\left(r^{2}=1\right)$. The exponential increase in the ratio would continue even if the insect flew to the outside (right) of the F concentration peak. Exponential relationships result for all Gaussian distri- 


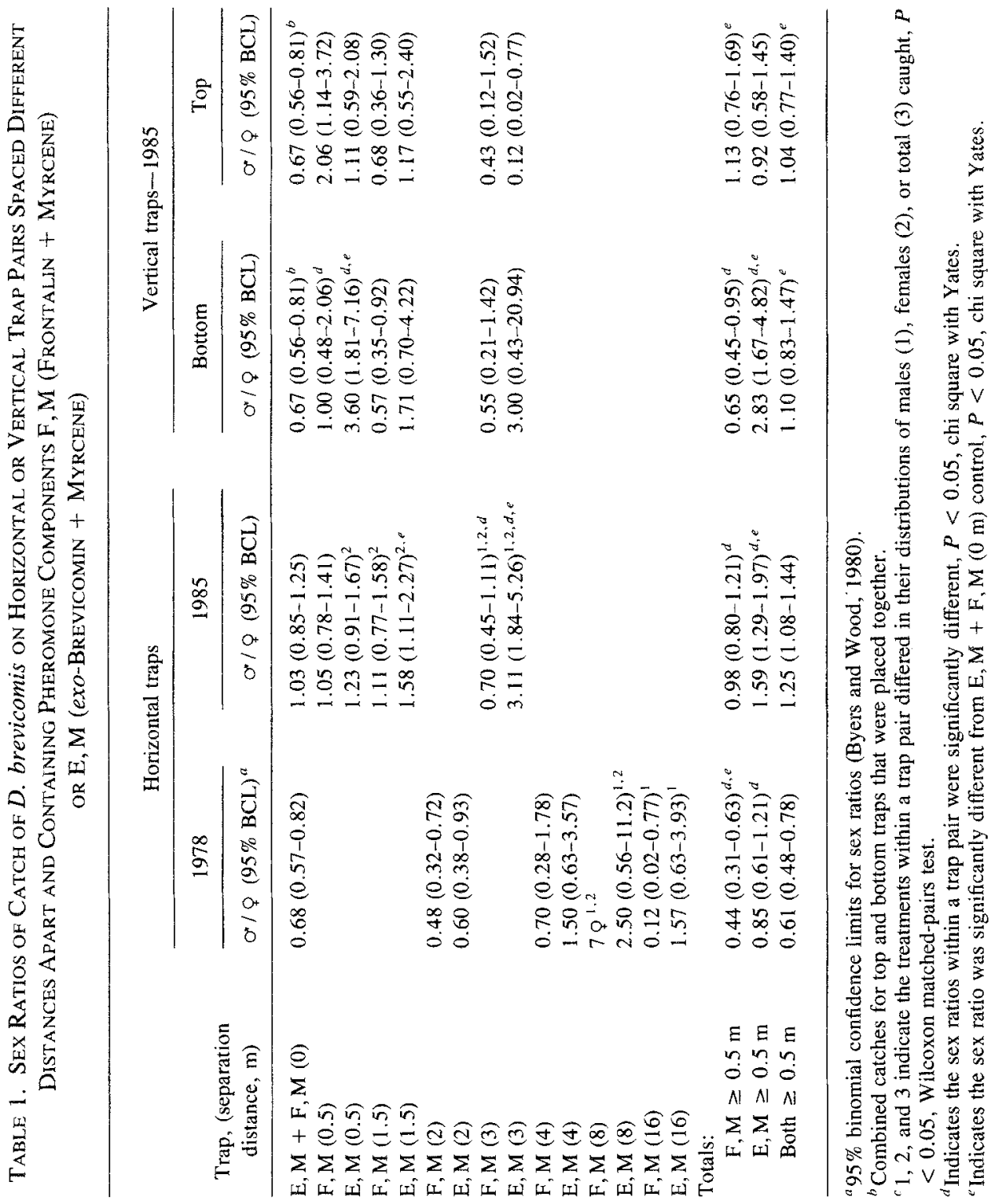


butions with equal variances. Ratio changes also occur for distributions with unequal variances, but the relationships are more complicated (but can be calculated with the ratio equation).

\section{DISCUSSION}

The release of $E, M$ and $F, M$ from separate points situated either vertically or horizontally might appear to be possible in nature on standing or fallen trees. However, a "pioneer' female would release E, M in small amounts only until she was joined by other females and males during the initial stages of the mass attack. Based on the results presented here, she would most likely attract a male to the area. Once both attractants are released from the pioneering pair, then a "balanced"' sex ratio occurs (Vité and Pitman, 1969a). As mentioned above, several earlier studies, and the present one, indicate that relatively more males are attracted to $\mathrm{E}, \mathrm{E}, \mathrm{M}$, or $\mathrm{E}+$ oleoresin while more females are attracted to F, F, M, or F + oleoresin. However, it must be noted that the respective attraction rates to each component were much less than to the synergistic blend.

There are no apparent differences between the sexes in attraction to a concentration range of $\mathrm{E}, \mathrm{F}, \mathrm{M}(1: 1: 1)$ covering five orders of magnitude in the laboratory (Byers and Wood, 1981) and three orders in the field (Tilden and Bedard, 1985). Thus, it is difficult to find an explanation for the sexual preferences for the respective components. It would not seem adaptive for a male to release $F$ unless he was with a female in her gallery, and males are not known to initiate attacks and "call" for females. Therefore, it would appear females never have the opportunity to respond to F alone. Although Libbey et al. (1974) did find $\mathrm{F}$ was released from male + male confinement in glass tubes, males never are found in galleries in this way (Byers et al., 1984). On the other hand, the male preference for $E$ could possibly be adaptive if males use it to seek females after landing on the tree. Could it be that these sexual preferences are the "behavioral remnants" of a previous era when the sexes sought each other (true sex pheromones)? Later in evolution each sex could have relied on the opposite-sex component as the primary one that is synergized by the same-sex produced component. Analysis of the attraction response of each sex to various component ratios may indicate which component is synergizing which component or whether they are mutually synergistic (Byers, 1987).

Linn and Gaston (1981) have performed wind-tunnel tests with male cabbage looper moths in which two pheromone component plumes were allowed to intersect between 35 and $85 \mathrm{~cm}$ downwind of the sources. They found no effect on upwind orientation by separating the components $12 \mathrm{~cm}$ apart $(85-\mathrm{cm}$ downwind plume intersection), but when the separation was only $8 \mathrm{~cm}(35-\mathrm{cm}$ downwind intersection) there were significantly less moths approaching the 
sources. However, one of the components is attractive alone while the other is not, so the case is different than if neither component is significantly active alone, as in the Western pine beetle. The male moths were apparently "confused" as they flew out of the intersecting plumes (removal of the inactivealone component $35 \mathrm{~cm}$ downwind) during their upwind flight to the activealone component, as if they had suddenly passed by a female (full blend). When the plumes were further apart, the moths were essentially only flying up the active-alone plume, presumably in a long-range orientation mode.

In field studies with the Western pine beetle, the relationships between catch and component separation distance (Figures $1-3$ ) have underlying causes which are apparently very complex. In nature the wind direction can vary widely and, although the trap pairs were placed perpendicular to the prevailing wind, sometimes the wind carried the odor of one component directly through the source of the other component (this error should not have occurred with the vertically placed trap pairs). Considering a constant perpendicular mean wind direction, however, there are several differences between the geometries of the active spaces of an idealized plume of a two-component blend and that of two coalescing single-component plumes. For the coalescing plumes (Figure 5), the active space is narrower and shorter than in a normal blend, and the "head" of the active space is far from either source and oriented between the sources compared to a normal blend with the "head" at the source. Another difference is due to the fact that the periphery of a plume is more variable in time with regard to concentration (Elkinton and Cardé, 1984), and it is the peripheries of plumes that comprise the active space of coalescing plumes. Finally, Figure 5 shows the concentration ratios of the two components for a particular degree of plume intersection. This is quite different from the case with the normal blend where both components have corresponding Gaussian distributions. Significant effects on behavior of various component ratios are well known in moths (Roelofs, 1978; Roelofs and Cardé, 1977; Baker and Cardé, 1979) and, more recently, in bark beetles (Schlyter et al., 1987b; Tilden and Bedard, 1985; Byers, 1987). The theoretical relationships have been considered for time-averaged plumes which are, in fact, filamentary in an instantaneous sense (Okubo, 1980), but the theories here would still generally apply to such plumes.

The concept of using multicomponent pheromones in a blend that is released from many scattered sources in the field for mating disruption and insect control is well established. However, the field and theoretical results presented here indicate that release of the individual components from a mosaic mixture of sources may be more disruptive of olfactory communication than use of full blends. It is hoped that the considerations presented here on interacting component plumes will inspire new types of experiments at both basic and applied levels. 
Acknowledgments-I am appreciative of the USFS and W.D. Bedard, P.E. Tilden, and M.I. Haverty for providing the facilities for research in the field. I am especially grateful to P.E. Tilden who provided helpful assistance and information concerning my field studies. I would like to thank D.L. Wood, Department of Entomological Sciences, University of California, Berkeley, for providing me with a research base in collaboration with $J$. Löfquist and the Department of Animal Ecology, University of Lund, Sweden.

\section{REFERENCES}

BAKER, T.C., and CARDE, R.T. 1979. Analysis of pheromone-mediated behaviors in male Grapholitha molesta, the Oriental fruit moth (Lepidoptera: Tortricidae). Environ. Entomol. 8:956968 .

Bedard, W.D., Tllonen, P.E., Wood, D.L., Silverstein, R.M., Brownlee, R.G., and Rodin, J. . 1969. Western pine beetle: Field response to its sex pheromone and a synergistic host terpene, myrcene. Science 164:1284-1285.

Bedard, W.D., WoOd, D.L., Tilden, P.E., Lindahl, K.Q., JR., SIlverstein, R.M., and Rodin, J:O. 1980. Field response of the Western pine beetle and one of its predators to host- and beetle-produced compounds. J. Chem. Ecol. 6:625-641.

BRowNE, L.E. 1978. A trapping system for the Western pine beetle using attractive pheromones. J. Chem. Ecol. 4:261-275.

Browne, L.E., WoOd, D.L., BedArd, W.D., Silverstein, R.M., and West, J.R. 1979. Quantitative estimates of the Western pine beetle attractive pheromone components, exo-brevicomin, frontalin, and myrcene in nature. J. Chem. Ecol. 5:397-414.

BYERS, J.A. 1987. Novel diffusion-dilution method for release of semiochemicals: Testing pheromone component ratios on the Western pine beetle. $J$. Chem. Ecol. In press.

BYERS, J.A., and WOOD, D.L. 1980. Interspecific inhibition of the response of the bark beetles, Dendroctonus brevicomis and Ips paraconfusus, to their pheromones in the field. $J$. Chem. Ecol. 6:149-164.

BYERS, J.A., and WOOD, D.L. 1981. Interspecific effects of pheromones on the attraction of the bark beetles, Dendroctonus brevicomis and Ips paraconfusus in the laboratory. I. Chem. Ecol. $7: 9-18$.

Byers, J.A., Wood, D.L., Craig, J., and Hendry, L.B. 1984. Attractive and inhibitory pheromones produced in the bark beetle, Dendroctonus brevicomis, during host colonization: Regulation of inter- and intraspecific competition. J. Chem. Ecol. 10:861-877.

ElkiNTON, J.S., and CARdÉ, R.T. 1984. Odor dispersion, pp. 73-91, in W.J. Bell and R.T. Cardé (eds.). Chemical Ecology of Insects. Chapman and Hall, London.

Hughes, P.R., and PITMAN, G.B. 1970. A method of observing and recording the flight behavior of tethered bark beetles in response to chemical messengers. Contrib. Boyce Thompson Inst. $24: 329-336$.

HugheS, P.R., and RENWICK, J.A.A. 1977. Hormonal and host factors stimulating pheromone synthesis in female Western pine beetles, Dendroctonus brevicomis. Physiol. Entomol. 2:289292.

Kinzer, G.W., Fentiman, A.G., JR., Page, T.F., Jr., Vité, J.P., and Pitman, G.B. 1969. Bark beetle attractants: Identification, synthesis and field bioassay of a new compound isolated from Dendroctonus. Nature 211:477-478.

Libbey, L.M., Morgan, M.E., Putnam, T.B., and Rudinsky, J.A. 1974. Pheromones released during inter- and intra-sex response of the scolytid beetle Dendroctonus brevicomis. J. Insect Physiol. 20:1667-1671. 
LinN, C.E., JR., and GASTON, L.K. 1981. Behavioral function of the components and the blend of the sex pheromone of the cabbage lopper, Trichoplusia ni. Environ. Entomol. 10:751-755.

OKuBo, A. 1980. Diffusion and Ecological Problems: Mathematical Models. Springer-Verlag, Berlin, p. 58.

PitMAN, G.B., and Vité, J.P. 1971. Predator-prey response to Western pine beetle attractants. $J$. Econ. Entomol. 64:402-404.

PitMan, G.B., Vité, J.P., Kinzer, G.W., and Fentiman, A.F., JR. 1969. Specificity of population-aggregating pheromones in Dendroctonus. J. Insect Physiol. 15:363-366.

RoElofS, W.L. 1978. The threshold hypothesis for pheromone perception. J. Chem. Ecol. 4:685699.

Roelofs, W.L., and CARDE, R.T. 1977. Responses of Lepidoptera to synthetic sex pheromone chemicals and their analogues. Annu. Rev. Entomol. 22:377-405.

SCHLYTER, F., BYERS, J.A., and LöFQVIST, J. 1987a. Attraction to pheromone sources of different quantity, quality and spacing: Density-regulation mechanisms in the bark beetle Ips typographus. J. Chem. Ecol. 13:1503-1523.

SCHLYTER, F., LÖFQVIST, J., and BYERS, J.A. 1987b. Behavioural sequence in the attraction of the bark beetle Ips typographus to pheromone sources. Physiol. Entomol. 12:185-196.

Silverstein, R.M., Brownlee, R.G., Bellas, T.E., Wood, D.L., and Browne, L.E. 1968. Brevicomin: Principal sex attractant in the frass of the female Western pine beetle. Science 159:889-891.

Slade, D.H. (ed.) 1968. Meteorology and Atomic Energy. US Atomic Energy Commission, Oak Ridge, Tennessee

TILDEN, P.E., and BEDARD, W.D. 1985. Field response of Dendroctonus brevicomis to exo-brevicomin, frontalin, and myrcene released at two proportions and three levels. J. Chem. Ecol. 1 1:757-766.

VITÉ, J.P, and PITMAN, G.B. 1969a. Aggregation behavior of Dendroctonus brevicomis in response to synthetic pheromones. J. Insect Physiol. 15:1617-1622.

VITÉ, J.P., and PITMAN, G.B. 1969b. Insect and host odors in the aggregation of the Western pine beetle. Can. Entomol. 101:113-117.

VITÉ, J.P., BAKKE, A., and RENwICK, J.A.A. 1972. Pheromones in Ips (Coleoptera: Scolytidae): Occurrence and production. Can. Entomol. 104:1967-1975.

WoOD, D.L. 1982. The role of pheromones, kairomones, and allomones in the host selection and colonization behavior of bark beetles. Annu. Rev. Entomol. 27:411-446.

Wood, D.L., Browne, L.E., Ewing, B., Lindahl, K., Bedard, W.D., Tilden, P.E., Mori, K., Prrman, G.B., and Hughes, P.R. 1976. Westem pine beetle: Specificity among enantiomers of male and female components of an attractant pheromone. Science 192:896-898. 